Revue bibliographique pour le domaine irano-aryen

\title{
Rahim Shayegan, "Persianism: Or Achaemenid Reminiscences in the Iranian and Iranicate World(s) of Antiquity"
}

\section{Florence Somer}

\author{
(2) OpenEdition \\ Journals \\ Édition électronique \\ URL : http://journals.openedition.org/abstractairanica/49833 \\ DOI : 10.4000/abstractairanica.49833 \\ ISBN : 1961-960X \\ ISSN : 1961-960X \\ Éditeur : \\ CNRS (UMR 7528 Mondes iraniens et indiens), Éditions de l'IFRI
}

Référence électronique

Florence Somer, « Rahim Shayegan, "Persianism: Or Achaemenid Reminiscences in the Iranian and Iranicate World(s) of Antiquity" », Abstracta Iranica [En ligne], Volume 40-41 | 2019, document 14, mis en ligne le 30 décembre 2019, consulté le 17 avril 2021. URL : http://journals.openedition.org/ abstractairanica/49833 ; DOI : https://doi.org/10.4000/abstractairanica.49833

Ce document a été généré automatiquement le 17 avril 2021.

Tous droits réservés 


\title{
Rahim Shayegan, "Persianism: Or Achaemenid Reminiscences in the Iranian and Iranicate World(s) of Antiquity"
}

\author{
Florence Somer
}

\section{RÉFÉRENCE}

Rahim Shayegan, "Persianism: Or Achaemenid Reminiscences in the Iranian and Iranicate World(s) of Antiquity" in R. Strootman, M.J. Versluys (eds.). Persianism in Antiquity. Stuttgart: Franz Steiner, 2017 (Oriens et Occidens 25), p. 401-455

1 De la période parthe jusqu'à la fin de la domination sassanide en Iran, la vision d'une nation mythique sous la dynastie des Achéménides a fait émerger un "persianisme ", une identité culturelle et politique particulière associée à une période idéalisée de l'Iran ancien. Alors qu'il semble aisé de s'adonner à une relative appréhension historique des faits dans la littérature classique, la même recherche historiographique, permettant de séparer l'histoire du mythe, est relativement délicate dans l'étude de l'Iran antique. Cet article vise à isoler les traces tangibles de résurgence de la culture achéménide des Séleucides aux Sassanides concernant la titulature des rois, leurs fonctions et leurs attributs à travers les motifs iconographiques. Il vise également à démontrer l'existence de traces plus subtiles véhiculées à travers les siècles dans les contenus rédactionnels et discursifs. 


\section{AUTEURS}

\section{FLORENCE SOMER}

Doctorante EPHE, Mondes iranien et indien, Paris 